\title{
DESEMPLEO DE LARGA DURACIÓN, COLECTIVOS VULNERABLES Y LA REFORMULACIÓN DE LAS POLÍTICAS ACTIVAS DE EMPLEO ${ }^{\&}$
}

\author{
Long-term unemployment, vulnerable groups and the reformulation \\ of active employment policies \\ María Cristina Aguilar Gonzálvez*
}

Profesora contratada Doctora (acreditada a Profesora Titular)

Universidad de Cádiz (España)

\section{RESUMEN}

Reflexionamos en torno al acceso al mercado de trabajo de las personas vulnerables, desde el ámbito de las políticas de empleo por colectivos, y en presencia de la tan esperada regulación sistematizada de las políticas activas de empleo por el RD 818/2021, aprobado en septiembre de 2021, y estando en ejecución el Plan REINCORPORA-T, que partió del compromiso con las personas desempleadas de larga duración; esto es, con numerosos y variados colectivos vulnerables, destinatarios prioritarios de medidas de fomento del empleo, según la lista abierta que describe la Ley de Empleo en su art. 30.1, y que en la nueva regulación se ve amplificada y actualizada. La política de empleo "centrada en las personas", pero a la vez con un enfoque holístico, mirándolas desde su posición en el mercado de trabajo en atención a los rasgos y cualificación que aportan, deviene en la técnica más idónea. Habrá que prestar especial atención a los resultados que arroje la ejecución de los programas de activación y los que impliquen contratación, a ser empleados en la elaboración de medidas preventivas frente a futuras situaciones de desempleo.

Palabras clave: colectivos prioritarios, apoyo activo para el empleo, igualdad de oportunidades, Plan REINCORPORA-T, evaluación y prevención.

\section{ABSTRACT}

Our reflection is about the situation of vulnerable people in their access to the job market. We are focusing on their belonging to these groups. We are dealing with the expected systematized regulation of the active employment policies in Real Decreto 818/2021, sanctioned in September 2021, while the REINCORPORA-T Plan ("Join the job market again") is being carried out. This Plan emerged from the agreement with long-term unemployed people, for whom these employment promotion measures have been preferentially designed, according to the open list as described in the Employment Law (Ley de Empleo, art. 30.1), and that in the new regulation is amplified and updated. The "human-centred" employment policy, but at the same time with a holistic approach, looking at them from their position in the labor market in terms of the features and qualifications they bring, becomes the most suitable technique. Special attention should be paid to the results of the implementation of activation programs and those involving hiring, to be used in the development of preventive measures against future unemployment situations.

Keywords: preferencial groups, active support to employment, equal opportunities, REINCORPORA-T Plan, evaluation and prevention.

\& Este estudio parte de la Comunicación presentada en el VIII Congreso Red Española de Política Social (REPS 2021) «Cuidar la vida, garantizar la inclusión, convivir en diversidad: consensos y retos», en la MESA 5.1 sobre «Diseńo, evaluación e impacto de las políticas de empleo. En especial para los colectivos especialmente vulnerables». Bilbao, marzo 2021.

\footnotetext{
* Correspondencia a: María Cristina Aguilar Gonzálvez. C/ Enrique Villegas Vélez, n.o 1 (Cádiz), España. — cristina.aguilar@uca. es - https: //orcid.org/0000-0002-7252-0414

Cómo citar: Aguilar Gonzálvez, María Cristina. (2021). «Desempleo de larga duración, colectivos vulnerables y la reformulación de las políticas activas de empleow; Lan Harremanak, 46, 114-143. (https: //doi.org/10.1387/lan-harremanak.23178).
}

Recibido: 14 noviembre, 2021; aceptado: 21 diciembre, 2021.

ISSN 1575-7048 - elSSN 2444-5819 / (C) 2021 UPV/EHU 


\section{Consideraciones generales}

El estado general de incertidumbre, con tintes muy negativos, "que acecha» nuestro mercado de trabajo, va más allá del VUCA (Volatilidad, Uncertainty, Complejidad y Ambigüedad) que la lleva intrínseca; entorno al que se suman los efectos de la pandemia COVID, y ello nos hace dirigir la mirada hacia los colectivos vulnerables y su difícil posicionamiento en el mercado de trabajo español. La pertenencia al colectivo les lleva a la situación de desempleo de larga duración, y esto a su vez acentúa el peligro de la exclusión social, si no se puede paliar dicha vulnerabilidad a través de acciones positivas; esto es, el destino final es la pobreza, por lo que son necesarias medidas urgentes que rompan esta secuencia (Pérez, 2010: 37).

En 2021 en España, 11,8 millones personas se encuentran en riesgo de pobreza o exclusión social ( $25,3 \%$ de la población). Se ha producido una leve mejoría en la tasa general pero, de un lado, hay colectivos que no pueden superar dicho estado $^{1}$, de otro, la situación de pandemia ha afectado de forma drástica a ciertas ocupaciones tales como las de trabajadores de servicios de restauración y de comercio, o del sector de actividades administrativas y servicios auxiliares, en el que se ha recurrido más a los ceses o despidos que a los expedientes de regulación temporal de empleo (ERTEs, art. 47 TRET). En estados de alarma como los vividos, la situación de urgencia exigía paliativos inmediatos, no proyectos, y el recurso a medidas como los ERTEs, que aún siguen siendo prorrogados para evitar el aumento masivo del número de desempleados. Puesto que la baja cualificación propicia la salida del mercado de trabajo, resulta muy loable la exigencia que contiene la última prórroga de los ERTEs, a través del Real Decreto-ley 18/2021, de medidas urgentes para la protección del empleo, la recuperación económica y la mejora del mercado de trabajo (art. 3 y Disposición adicional tercera) ${ }^{2}$, del desarrollo de acciones formativas a favor de las personas trabajadoras afectadas por la reducción de jornada, que tendrán como objetivo la mejora de sus competencias profesionales y empleabilidad (incluyendo las vinculadas a la adquisición de competencias digitales, así como aquellas que permitan su recualificación, aunque no tengan relación directa con la actividad desarrollada en la empresa; en algunos supuestos, encaminadas a fomentar la transición profesional necesaria para afrontar los cambios económicos o tecnológicos que requieran una revisión de su organización), entre el 1 de noviembre de 2021 y el 28 de febrero de 2022, por parte de las empresas para poder acceder al beneficio de la cotización, en atención a la futura previsión legal sobre el Mecanismo de Sostenibilidad del Empleo (MSE) ${ }^{3}$.

${ }^{1}$ Informe AROPE, https://www.eapn.es/estadodepobreza/ (acceso a 8/11/2021).

2 BOE n. ${ }^{\circ} 233$, de 29 de septiembre.

3 FEDEA Policy Papers, «Por un mercado de trabajo moderno y resiliente. Informe del Grupo de Trabajo Mixto Covid-19", 2020/10, págs. 5-6. BOE n. ${ }^{\circ} 233$, de 29 de septiembre. Sobre el MSE, véase https://www.expansion.com/opinion/2021/09/23/614b4ee6468aebc60e8b4661.html (acceso a 30/10/2021). 
Estamos en tiempos de reformas. El Plan de Recuperación, Transformación y Resiliencia ${ }^{4}$, como factor esencial para impulsar el crecimiento y la creación de empleo durante los próximos años, presenta un ambicioso conjunto de inversiones en torno a cuatro vectores transversales de transformación necesaria: eje verde, eje digital, cohesión social y territorial, e igualdad de género. En el ámbito laboral, prevé un descenso gradual de la tasa de paro desde el 15,5\% en 2020 hasta el 12,7\% en 2024, gracias al impacto de las medidas de apoyo, en la recuperación de los niveles de actividad (Programa Nacional de Reformas, PNR 2021, pág. 6). La tasa de paro, en octubre 2021, se sitúa en el 14,57\%, lo que supone 69 centésimas menos que en el trimestre anterior; en el último año esta tasa ha descendido en 1,69 puntos ${ }^{5}$, pero hacen falta políticas públicas eficaces para alcanzar dichos objetivos ambiciosos.

El complejo marco normativo en políticas de fomento del empleo, en la situación actual del mercado de trabajo, requería una reformulación urgente, y ello derivado también de las exigencias de la digitalización del mercado laboral. Nuestra Ley de Empleo (en período de reforma), en su art. 36.2, declara la inclusión de las políticas activas de empleo en la acción protectora del desempleo, en una relación de prevalencia de estas últimas frente las prestaciones por desempleo de nivel contributivo y asistencial (literalmente, las políticas activas de empleo "se complementarán y se relacionarán, en su caso», con la protección por desempleo). En consonancia, el art. 206 Texto Refundido de la Ley General de Seguridad Social (TRLGSS) integra medidas procedentes de ordenamientos jurídicos diferentes, como son el Derecho del Empleo y el Derecho de la Seguridad Social, al afirmar que la acción protectora del desempleo comprende las prestaciones por desempleo de carácter contributivo y asistencial, «y las acciones que integran las políticas activas de empleo» ${ }^{6}$.

En esta labor de reestructuración de las políticas de empleo, entre otras, se ha adoptado el RD 818/2021, de 28 septiembre, por el que se regulan los programas comunes de activación para el empleo del Sistema Nacional de Empleo ${ }^{7}$, que adquiere la dimensión de norma central en la temática que nos ocupa, en respuesta al objetivo marcado en el Plan antes citado, en particular sobre la modernización de las políticas activas de empleo, a través de la previsión de medidas de fomento del empleo para los «colectivos prioritarios», a ser complementadas con la financiación que permita su ejecución ${ }^{8}$ : a grandes rasgos, para los

\footnotetext{
${ }^{4}$ https://planderecuperacion.gob.es/ (acceso a 8/11/2021).

5 https://www.ine.es/daco/daco42/daco4211/epa0321.pdf (acceso a 8/11/2021).

${ }^{6}$ Real Decreto Legislativo 8/2015, de 30 de octubre, por el que se aprueba el Texto Refundido de la Ley General de la Seguridad Social (BOE n. ${ }^{\circ} 31$, de 5 de febrero).

7 BOE n. ${ }^{\circ} 233$, de 29 de septiembre.

${ }^{8} \mathrm{https} / /$ www.lamoncloa.gob.es/temas/fondos-recuperacion/Documents/30042021-Plan_Recuperacion_\%20Transformacion_\%20Resiliencia.pdf (acceso a 25/10/2021). En la nota de prensa del MTYES, como carta de presentación de la nueva regulación, se indica que «permitirá simplificar,
} 
jóvenes (Plan de Choque por el Empleo Joven $2019-2021^{9}$ ) prevé que las primeras experiencias laborales y la formación en alternancia deriven de contratos formativos; para las mujeres, se centra en la promoción del empleo de calidad desde la igualdad entre hombres y mujeres (presente con carácter transversal en todos los programas), e incluye un programa de inserción sociolaboral para las víctimas de violencia de género; para las personas con discapacidad, refuerza las acciones específicas de orientación, establece medidas de fomento del empleo indefinido, mantiene las ayudas para la adaptación y establece una relación de colaboración y complementariedad con los centros especiales de empleo (artículo 47.2.b), así como con las cooperativas de trabajo asociado y las sociedades laborales (artículo 47.3); para los mayores de 45 años, establece mecanismos para evitar su discriminación en el empleo en razón de la edad; para las personas en riesgo o situación de exclusión social, itinerarios personalizados de inserción en colaboración con empresas de inserción y sus entidades promotoras, entidades sin ánimo de lucro y empresas que los contraten.

Puesto que las personas encuadrables en alguno de los colectivos vulnerables-prioritarios para las políticas de empleo, debido a sus especiales dificultades, son propensas a caer en situación de desempleo de larga duración, como común denominador, se convierten doblemente en destinatarias de medidas activas de empleo, en tanto que sufren una discriminación múltiple. Por ello el recurso a instrumentos como el Plan trienal para prevenir y reducir el Desempleo de Larga Duración 2019-2021 ${ }^{10}$, conocido como Plan REINCORPORA-T, con un ámbito subjetivo de aplicación muy amplio, derivado de su carácter preventivo frente a la larga duración en desempleo, que no se limita al tiempo sin empleo: esto es, atiende a desempleados durante 12 meses en los últimos 18 meses, a inscritos durante 180 días en los 9 meses anteriores mayores de 45 años o trabajadores agrarios, e incluye a más colectivos vulnerables de los que hasta el momento han figurado de forma expresa; nos referimos a los trabajadores domésticos, los cuidadores no profesionales, y a las personas en procesos de regulación de empleo, entre otros.

Se trata de un Plan que incide en las políticas de reincorporación en el mercado de trabajo y de mejora de la protección económica de la contingencia, en una combinación de medidas de política activa y pasiva de empleo en aplicación de la coordinación impuesta en el art. 41 TRLE. Entre los objetivos cuantificados, implica un descenso en el $40 \%$ de los desempleados de larga duración

\footnotetext{
la gestión y la normativa vigente, actualizar los programas y aumentar su eficacia», https://prensa.mites.gob.es/WebPrensa/noticias/laboral/detalle/4030 (acceso a 25/10/2021).

9 Resolución de 7 de diciembre de 2018, de la Secretaría de Estado de Empleo, por la que se publica el Acuerdo del Consejo de Ministros de 7 de diciembre (BOE n. ${ }^{\circ}$ 296, de 8 de diciembre).

${ }^{10}$ Se aprueba por la Resolución de 8 de abril de 2019, de la Secretaría de Estado de Empleo, por la que se publica el Acuerdo del Consejo de Ministros de 5 de abril de 2019 (BOE n. ${ }^{\circ}$ 85, de 9 de abril).
} 
(PLD), con el objetivo de reducir en 2.5 puntos, y llegar hasta el 4,3\%, la tasa de parados de larga duración a finales de 2021.

Sin embargo si se teclea en Google «desempleados de larga duración» ${ }^{11}$, el Servicio Público de Empleo Estatal (SEPE) lleva directamente a los requisitos para ser beneficiario de la Renta Activa de Inserción (RAI): no conecta con el Plan REINCORPORA-T. Al margen de que quizás los afectados no sean los destinatarios directos de la web del SEPE, en aplicación de la regla de la coordinación subordinada de las políticas pasivas a las activas, la condizionalità o que el seguimiento de la actividad ofertada por los servicios de empleo (activación del desempleado), "condicione» el disfrute de una prestación sustitutiva del salario (art. 41.4 Texto Refundido de la Ley de Empleo, TRLE ${ }^{12}$; Aguilar, 2019) es la regla. "iActívate!» debiera ser el mensaje, siempre de la manera más acorde a sus características personales, y desde la orientación profesional individualizada por parte de los agentes de intermediación laboral, en cumplimiento de lo que debiera ser «su compromiso de actividad» recíproco con el demandante de empleo.

La activación se complementa con la cobertura económica temporal a la que se tenga derecho (de nuevo el SEPE), según las circunstancias y tiempo en desempleo, guiada por la máxima make work pay, y sobre la base, como objetivo prioritario, de la formación "adecuada al mercado" como salto hacia el empleo. Se trata de evitar, en todo caso, llegar a la última red de protección del sistema, esto es, a recursos como la Renta activa de inserción o el Ingreso mínimo vital.

Movidos por el Plan REINCORPORA-T en ejecución, y por la reordenación de las políticas activas de empleo a través del RD 818/2021, planteamos una reflexión acerca de los colectivos vulnerables, destinatarios prioritarios de medidas de fomento del empleo, y el tránsito hacia su salida de la situación de desempleo de larga duración, a la que les lleva los rasgos causantes de su vulnerabilidad en el mercado de trabajo, a través de los "programas comunes de empleo», que convivirán con programas autonómicos propios (Disposición Adicional $\left.1 .^{\mathrm{a}}\right)^{13}$ y locales (Disposición Adicional 12.a).

11 https://www.sepe.es/HomeSepe/Personas/distributiva-prestaciones/he-dejado-de-cobrar-elparo/no-tengo-prestacion/desempleado-larga-duracion.html (acceso a 5/10/2021).

12 Real Decreto Legislativo 3/2015, de 23 de octubre, por el que se aprueba el Texto Refundido de la Ley de Empleo (BOE n. ${ }^{\circ} 255$, de 24 de octubre).

13 Resolución de 10 de junio de 2021, por la que se dispone la publicación del Convenio entre el Servicio Público de Empleo Estatal O.A. y la Comunidad Autónoma de Canarias para el desarrollo de un Plan Integral de Empleo de Canarias que comprenda la realización de medidas que incrementen el empleo, de acuerdo con lo establecido en la Disposición adicional centésima vigésima de la Ley 11/2020, de 30 de diciembre, de Presupuestos Generales del Estado para el año 2021 (BOC n. ${ }^{\circ}$ 127, de 22 de junio), http://www.gobiernodecanarias.org/boc/2021/127/007.html (acceso a 19/10/2021), con financiación del SEPE se acometerán medidas activas de empleo; en particular, este Plan de Empleo autonómico señala entre sus objetivos «desarrollar actuaciones singulares dirigidas a personas que se encuentran en desempleo de larga duración y aquellas otras especialmente vulnerables ante el empleo, en línea con el Plan REINCORPORA-T (2019-2021). 


\section{2. Ámbito subjetivo o colectivos «prioritarios» de entre los «vulnerables», destinatarios de medidas de política activa de empleo en cada período}

Partimos de la idea de que las normas en política de empleo delimitarán quiénes son los colectivos prioritarios a los que atender, en un marco temporal y espacial concreto. Dichos colectivos destinatarios, estarán entre los vulnerables que figuran, o no, entre los mencionados expresamente en el marco general que traza la Ley de Empleo en su art. 30; a los que, en atención a «sus especiales circunstancias» el Gobierno y las Comunidades Autónomas les dedicarán «programas específicos destinados a fomentar su empleo», precisamente por ser "personas con especiales dificultades de integración en el mercado de trabajo» (de forma más correcta, «los colectivos que tienen mayor dificultad en el acceso o permanencia en el empleo", como indica el art. 10.4 de la misma norma y de acuerdo con la nota a pie de página n. ${ }^{\circ} 68$ Bengoetxea, 2020: 36). Y continúa diciendo dicho artículo clave en el objeto de nuestro estudio,

teniendo en cuenta las especiales circunstancias de estos colectivos, los Servicios Públicos de Empleo asegurarán el diseño de itinerarios individuales y personalizados de empleo que combinen las diferentes medidas y políticas, debidamente ordenadas y ajustadas al perfil profesional de las personas que los integran y a sus necesidades específicas.

Esto es, partiendo del servicio público de intermediación laboral (art. 31 TRLE), se está invocando a las políticas activas de empleo, definidas en la propia Ley como

conjunto de servicios y programas de orientación, empleo y formación profesional para el empleo en el ámbito laboral dirigidas a mejorar las posibilidades de acceso al empleo, por cuenta ajena o propia, de las personas desempleadas, al mantenimiento del empleo y a la promoción profesional de las personas ocupadas y al fomento del espíritu empresarial y de la economía social (art. 36 TRLE).

La primera cuestión pasa por delimitar el concepto de «colectivos vulnerables» a los efectos de las políticas de empleo y su inserción en el mercado de trabajo: qué individuos forman el grupo y, por su pertenencia a los mismos, son destinatarios de ciertas medidas de acción positiva encaminadas al fin de su colocación. La doctrina se ha manifestado en el sentido de ausencia de un concepto jurídico-positivo de "colectivo vulnerable» (Bengoetxea, 2020: 21; Fernández, 2016; Miñarro, 2017) que, sin embargo, sí existe desde la sociología, y que podemos «imaginar» desde la observación a nuestro alrededor y de la consulta de datos estadísticos sobre el mercado de trabajo. Del mismo modo se ha argumentado que la falta de una enumeración exhaustiva de los colectivos en tal situación, actúa en detrimento de la seguridad jurídica en la aplicación de las actuaciones de inserción laboral diseñadas para ellos. 
Los orígenes de la noción de vulnerable groups se encuentra en la normativa internacional protectora de los derechos humanos, de colectivos con dificultades específicas que derivan de rasgos personales o de sus características grupales. La OIT, desde su Constitución de 1919, ya se centra en ciertos colectivos (niños, adolescentes, mujeres, pensionistas de vejez e invalidez, ocupados en el extranjero), a los que con posterioridad ofrecerá cobertura a través de sus Convenios (Fernández, 2019: 127) ${ }^{14}$. Se trata de minorar riesgos de condiciones de vida y trabajo precarias, en contraposición con el «trabajo decente» o digno del que todas las personas deben disfrutar, con una mayor incidencia en tiempos de cri$\operatorname{sis}^{15}$. Es de destacar asimismo la labor del Tribunal Europeo de Derechos Humanos y de la ONU a través de sus Tratados Internacionales sobre refugiados, en atención a la raza, mujeres, infancia, migrantes y personas con discapacidad (Bengoetxea, 2020: 21-23).

La OIT define la "vulnerabilidad ante el empleo» como el riesgo de permanecer sin empleo y de estar en situación de pobreza en el trabajo a largo plazo ${ }^{16}$. Como factores de vulnerabilidad, "saltando» del ámbito internacional hacia el Plan estatal REINCORPORA-T, este último destaca el género, en especial, ser mujer, quienes sufren en el mercado de trabajo de una mayor temporalidad, una parcialidad involuntaria en la contratación, y prestan servicios en los sectores más afectados por las crisis, tales como la hostelería, turismo, comercio, construcción, agricultura. La edad funciona asimismo como otro de los factores, en distintas etapas de la vida: jóvenes, mayores de 45 años, mayores de 55 (Domínguez, 2018: 361). El nivel educativo, incide en la capacidad mayor o menor de adaptación a las circunstancias del mercado: las personas sin estudios de FP o universitarios, muestran un nivel de adaptación menor a las distintas exigencias vertiginosas que plantea. Cuestiones relativas al origen de las personas, como su nacionalidad, hace que los inmigrantes, de ocupar puestos de trabajo, se trate de empleo temporal, precario, en sectores específicos como la construcción. Otra cuestión relevante es la función que viniera desarrollando antes de la crisis, puestos de gerentes y/o extrabajadores autónomos, verán descender sus niveles de vida y condiciones laborales, cuestión nada fácil a nivel psicológico, y en otra multiplicidad de aspectos (Pérez, 2010: 38-39).

$14 \mathrm{Si}$ en el buscador de la web de la OIT tecleamos «colectivos vulnerables», nos lleva a personas con enfermedades, mujeres, niños, trabajadores agrícolas, trabajadores informales, trabajadores domésticos. Y se refiere a trabajadores vulnerables (frente a los permanentes) o a excluidos, a empleos vulnerables; con expresiones como "discriminados, marginados o vulnerables», "trabajadores precarios y vulnerables».

15 «El trabajo decente es como una fuerte soga que ha demostrado ser capaz de sacar a las personas y a la sociedad de las crisis, colocándolas en el camino del desarrollo sostenible», «Trabajo, paz y resiliencia", https://www.ilo.org/global/topics/employment-promotion/recovery-and-reconstruction/ lang--es/index.htm (acceso a 8/03/2021).

16 Documento divulgativo sobre el Plan REINCORPORA-T en la web del SEPE, pág. 8. 
En nuestra opinión, el concepto jurídico-positivo de "colectivos vulnerables» existe, indirectamente, desde el Derecho del Empleo, a los efectos de la inclusión laboral de las personas encuadrables en los mismos y, por tanto, desde la necesidad de medidas de fomento del empleo: son los que para esta rama del ordenamiento jurídico adquieren, en cada período, el papel de "colectivos prioritarios» en tanto que destinatarios de medidas de política activa de empleo. El art. 30.1 TRLE ofrece un listado compuesto por ocho colectivos, ampliable; tras la Ley de Empleo 56/2003, que en su art. 26 mencionaba como colectivos prioritarios a «jóvenes, mujeres, parados de larga duración mayores de 45 años, discapacitados e inmigrantes, con respeto a la legislación de extranjería" sin contemplar «otros» (que se añadió en la modificación de 12/02/2011), la Ley 44/2007 para la regulación de las de Empresas de Inserción ${ }^{17}$, a los fines de determinar quiénes pueden ser trabajadores en ellas, se refiere a "personas en situación de exclusión social desempleadas e inscritas en los Servicios Públicos de Empleo, con especiales dificultades para su integración en el mercado de trabajo, que estén incluidos en alguno de estos colectivos», que enumera a continuación en su artículo 2, en una lista cerrada que reproduce, salvo en las dos últimas entradas, la

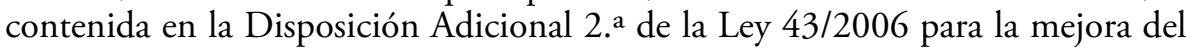
crecimiento y del empleo ${ }^{18}$; y la normativa autonómica complementaria puede añadir colectivos, como el Decreto de la Junta de Andalucía 193/2010, de 20 de abril, por el que se regula la calificación y se crea el Registro de Empresas de Inserción de Andalucía y el Decreto 155/2017 que lo modifica ${ }^{19}$, algunos de los cuales han sido incorporados al listado más actualizado del que disponemos, sin ser completo o exhaustivo en respuesta a la casuística del momento, que nos ofrece el RD 818/2021, de 28 septiembre, por el que se regulan los programas comunes de activación para el empleo del Sistema Nacional de Empleo, en cuyo art. 5 define a las personas destinatarias de los mismos. Esta norma incluso va más allá, porque identifica como "colectivos especialmente vulnerables» a las personas con discapacidad y en riesgo o en situación de exclusión social; afina en la distinción entre «en riesgo» de exclusión social, y la ya materializada situación de exclusión. Se encuentran en la primera los jóvenes, las mujeres, las personas trabajadoras de edad avanzada, las personas con discapacidad (calificadas de «especialmente vulnerables» como acabamos de señalar) y los inmigrantes, entre otros (Areta, 2010: 250).

Por tanto, y con afán compilatorio, cuando desde la perspectiva de las políticas activas de empleo (PAE) se atiende a los colectivos vulnerables como colectivos prioritarios en fomento del empleo, nos referimos a un ámbito subjetivo

17 BOE n.o 299, de 14 de diciembre, actualizada a 2012.

18 BOE n.o 312, de 30 de diciembre, en versión consolidada de mayo 2021.

19 BOJA n.o 90, de 11 de mayo de 2010; BOJA n.o 193, de 6 de octubre de 2017. https:// www.juntadeandalucia.es/organismos/sae/areas/mejora-empleabilidad/empresas-insercion.html (acceso a $15 / 10 / 2021)$. 
muy amplio compuesto por jóvenes, con particular atención a aquellos con déficit de formación, mujeres, parados de larga duración (que enfocamos además como consecuencia de la vulnerabilidad), mayores de 45 años, personas con responsabilidades familiares («no compartidas», añade el art. 59.1,f RD 818/2021), mujeres víctimas de violencia de género, mujeres víctimas de trata de seres humanos, inmigrantes, los colectivos especialmente vulnerables antes especificados, estando en él los que se encuentran en riesgo o situación de exclusión social (consecuencia última derivada tanto de la vulnerabilidad como de la situación de desempleo de larga duración) y las personas con discapacidad (redundante puesto que están en riesgo o están en la situación inmediatamente antes descrita); se añaden las personas perceptoras de rentas mínimas de inserción o del ingreso mínimo vital (IMV), las personas drogodependientes en proceso de rehabilitación, personas internas en centros penitenciarios, personas exreclusas, minorías étnicas (art. 59.1 RD), y personas trans que lo acrediten (art. 59.2 $\mathrm{RD})$; teniendo todos en común la situación de desempleo y su inscripción como demandante de empleo.

Pero también como destinatarios de estos programas pueden encontrarse personas ocupadas, por ejemplo, en empresas de inserción, e incluso los «trabajadores pobres» o "pobres con trabajo», ya mencionados en el Consejo Europeo de Niza en el año 2000, que en España superan la media de la Unión Europea, porque el empleo precario no constituye un medio para garantizar unas condiciones de vida dignas, y las nuevas realidades en el mercado plantean riesgos de precarización del trabajo y de pérdida de los estándares de calidad de vida de la población (art. 59. 1 RD 818/2021, Cruz, 2019: 240, Pérez, 2010: 40-41 y Carril, 2021: 73-74); también, siguiendo el Plan REINCORPORA-T los trabajadores agrarios, y los trabajadores domésticos; en atención a dicho Plan, asimismo los cuidadores no profesionales, y personas en procesos de regulación de empleo.

Y siempre pueden sumarse otros colectivos, lo que convierte la lista en abierta, en virtud de esa coletilla del punto 1, del art. 30 TRLE, «u otros que se puedan determinar, en el marco del Sistema Nacional de Empleo», como los refugiados (Mińarro, 2017); o como ya venía haciendo el antes mencionado Decreto 193/2010, de 20 de abril, por el que se regula la calificación y se crea el Registro de Empresas de Inserción de Andalucía y el Decreto 155/2017 que lo modifica, añadiendo en su momento a las víctimas de violencia de género, y a las personas incluidas en alguno de los siguientes grupos: personas emigrantes retornadas a Andalucía con graves necesidades personales o familiares, personas que tengan a su cargo una familia monoparental y presenten graves necesidades personales o familiares, personas desempleadas mayores de 50 ańos que hubiesen permanecido inscritas de forma ininterrumpida como demandantes de empleo en una oficina de los Servicios Públicos de Empleo durante, al menos, doce meses, personas con discapacidad física, intelectual o sensorial, en un grado 
igual o superior al 33\%, personas que presenten una situación de exclusión similar a las relacionadas en los párrafos anteriores, a propuesta del Servicio Andaluz de Empleo (art. 5.2 Decreto 193/2010), esto es, para el ámbito concreto de una Comunidad Autónoma.

No puede dejar de ser un listado «vivo», puesto que se trata de atender a las personas que lo necesitan en cada momento, y según el territorio (en el marco de la unidad del mercado de trabajo ${ }^{20}$ : la importancia de la dimensión local, que la Ley de Empleo plasma en su art. 4. Habrá que estar, por tanto, al ámbito de aplicación de cada norma en política de empleo para conocer a sus destinatarios, y vigencia.

En este sentido, el RD 818/2021, en su art. 4 sobre selección de participantes en los programas y, en concreto, su punto 2, otorga un amplio margen de decisión a los Servicios Públicos de Empleo, al indicar que «determinarán, en cada caso, el criterio de preferencia», siempre entre los colectivos que, con carácter general, puedan caer en desempleo de larga duración por presentar mayores dificultades de integración laboral, y de forma coordinada con los Servicios Sociales cuando fuera preciso. El protagonismo de los Servicios Públicos de Empleo se refuerza tanto más si los programas incluyen contratación, prevaleciendo los criterios y procedimientos establecidos por ellos mismos, al margen de que la entidad promotora sea Administración Pública.

Y ello desde una perspectiva holística (siendo este el adjetivo empleado en la norma), complementando el perfil del demandante con los perfiles demandados por el mercado de trabajo. Se observa que se insiste en el acercamiento real a las necesidades tanto de la persona como del entorno laboral.

Pensamos que la norma de esta forma responde al Componente 23 del Plan de Recuperación Transformación y Resiliencia, denominado «Nuevas políticas

${ }^{20}$ Como ejemplo, en octubre de 2021 se ha aprobado un polémico RD que regula la concesión directa de subvenciones por parte del SEPE, para la puesta en marcha de experiencias piloto en Navarra, País Vasco, Comunidad Valenciana y Extremadura, caracterizadas porque atenderán a mercados laborales muy diferenciados, "lo que posibilitará estudiar y evaluar cómo operan en circunstancias económicas y sociales diversas»: «El Gobierno aprueba destinar 9 M euros a proyectos territoriales a través de 1.200 iniciativas para el reequilibrio y la equidad», https://prensa.mites.gob.es/WebPrensa/noticias/laboral/detalle/4039 (acceso a 25/10/2021). Por otro lado, Orden TES/527/2021, de 26 de mayo, por la que se distribuyen territorialmente para el ejercicio económico de 2021, para su gestión por las Comunidades Autónomas con competencias asumidas, créditos del ámbito laboral financiados con cargo a los Presupuestos Generales del Estado, no financiados con el Mecanismo de Recuperación y Resiliencia, incluyendo aquellos destinados a la ejecución del Plan de Choque por el Empleo Joven 2019-2021 y del Plan Reincorpora-T 2019-2021 (BOE n. ${ }^{\circ} 129$, de 31 de mayo), cuyo objeto es dar publicidad a los criterios objetivos de la distribución territorial para el ejercicio económico 2021, entre las distintas Comunidades Autónomas con competencias de gestión asumidas, de los créditos, no financiados con cargo al Mecanismo de Recuperación y Resiliencia, correspondientes a servicios y programas del ámbito laboral, que se recogerán en el Plan Anual de Política de Empleo para 2021 (art. 1). 
públicas para un mercado de trabajo dinámico, resiliente e inclusivo», en combinación con algunas inversiones dentro del Componente 19, o Plan nacional de competencias digitales, que contemplan medidas para implementar las políticas activas de empleo a través del SEPE. El conjunto de las inversiones incluidas en dichos componentes está alineado con un «enfoque centrado en las personas» (expresión que utiliza la OIT en su Declaración del Centenario para el futuro del trabajo $^{21}$ ) y en el tejido productivo.

\section{El nuevo marco normativo de las políticas activas de empleo en España}

\subsection{Fundamentos jurídicos}

La adopción necesaria de medidas de política activa responde al deber de reequilibrar la igualdad en el acceso al empleo como derecho fundamental reconocido en la Constitución española (CE, arts. 1, 9.2 y 14), y en virtud del derecho al trabajo previsto en el art. $35 \mathrm{CE}$ para todos los ciudadanos de la Unión Europea (no ya solo para «todos los españoles»), incluidos los pertenecientes a colectivos vulnerables. Pero como el modelo del pleno empleo no deja de ser un modelo ideal, la CE prevé el derecho a una protección por desempleo desde el régimen público y universal de Seguridad Social en su art. 41, así como medidas de fomento del empleo puesto que los poderes públicos, de manera especial, realizarán una política orientada al pleno empleo; por lo que el art. 40, en combinación con el 9.2 CE, señala que «corresponde a los poderes públicos promover las condiciones para que la libertad y la igualdad del individuo y de los grupos en que se integra sean reales y efectivas; remover los obstáculos que impidan o dificulten su plenitud y facilitar la participación de todos los ciudadanos en la vida política, económica, cultural y social». Las políticas activas de empleo se presentan como herramienta clave de fomento del empleo, si bien no constituyen la única posibilidad dentro del grueso de las políticas públicas (Cruz 2019: 241).

De otro lado, en aplicación del art. 9.2 CE, en tanto que necesitados de medidas de acción positiva para garantizarles la igualdad de oportunidades y alcanzar la igualdad material, desde los artículos 1 de la Carta de Derechos Fundamentales de la Unión Europea ${ }^{22}$, que apela a la dignidad como seres humanos para salvar los obstáculos en su ejercicio, y a la prohibición de discriminaciones en su art. 21 en conexión con el 20 y su reconocimiento a la igualdad ante la

${ }^{21}$ https://www.ilo.org/wcmsp5/groups/public/@ed_norm/@relconf/documents/meetingdocument/wcms_711699.pdf; y a fecha 31/10/2021, con motivo de la Cumbre G20, la OIT se refiere a «una recuperación centrada en las personas tras la COVID-19», https://www.ilo.org/global/aboutthe-ilo/newsroom/news/WCMS_826091/lang--es/index.htm (acceso a 2/11/2021).

${ }^{22}$ DOUE C 202, de 7 de junio de 2016. 
ley (Fernández, 2016: 114), entran en juego los arts. 17 Texto Refundido de la Ley del Estatuto de los Trabajadores (TRET) o la no discriminación en las relaciones laborales, con la posibilidad abierta al establecimiento de «medidas de reserva, duración o preferencia en el empleo" que tengan por objeto facilitar la colocación de trabajadores demandantes de empleo (en el n. ${ }^{\circ} 3$ ); y el art. 30 TRLE, que como decimos presenta un listado abierto de "colectivos prioritarios». A lo que se suma el 35.1 TRLE, que reitera la prohibición de discriminaciones, tanto directas como indirectas, en el acceso al empleo, responsabilizando a los Servicios Públicos de Empleo, a sus entidades colaboradoras y a las agencias de colocación de velar en este sentido en la actividad de la intermediación laboral.

Por su parte el Pilar Europeo de Derechos Sociales, en su principio n. ${ }^{\circ} 4$ se refiere al "apoyo activo para el empleo», desde una asistencia personalizada y oportuna a fin de mejorar las perspectivas de empleo o trabajo autónomo, que incluye el derecho a recibir ayuda para la búsqueda de empleo, la formación y el reciclaje. Ello complementado con el derecho a la protección social y a la formación durante las transiciones profesionales. En relación a las personas desempleadas, concreta el derecho a recibir una ayuda personalizada, continuada y adecuada y, en particular sobre los desempleados de larga duración, se les reconoce el derecho a una evaluación individual detallada, a más tardar, a los 18 meses de desempleo.

En aplicación del mismo, las Orientaciones para las políticas de empleo de los Estados miembros en el año 2021, las mismas que en 2020 puesto que han sido prorrogadas, tal y como se indica en el art. 1 Decisión del Consejo (UE) 2021/1868, de 15 de octubre de $2021^{23}$, obliga a los Estados miembros a proporcionar a los desempleados y a las personas inactivas una asistencia eficaz, oportuna, coordinada e individualizada basada en el apoyo a la búsqueda de empleo, la formación, el reciclaje y el acceso a otros servicios de capacitación, "prestando especial atención a los grupos y personas vulnerables»: estrategias globales que incluyan evaluaciones individuales detalladas de los desempleados, a más tardar a los 18 meses de estar en desempleo, para prevenir y reducir significativamente el desempleo estructural y de larga duración (Orientación n. ${ }^{\circ} 6$ ). El Plan REINCORPORA-T marca el objetivo de entre 6-12 primeros meses en los supuestos de mayores de 45, mujeres, y otros grupos vulnerables.

Las directrices en política de empleo insisten en que los Estados miembros deben reforzar la eficacia de las políticas activas del mercado de trabajo, y ello desde la mejora de la interacción con los Servicios Sociales, y desde unos Servi-

23 DOUE L 379, de 26 de octubre. Anexo del CONSEJO, Decisión (UE) 2020/1512, de 13 de octubre, relativa a las orientaciones para las políticas de empleo de los Estados miembros (DOUE L 344, de 19 de octubre). 
cios Públicos de Empleo más eficaces y eficientes que garanticen una asistencia personalizada, prestando apoyo a las necesidades actuales y futuras del mercado laboral y aplicando sistemas de evaluación del rendimiento. Así mismo deben facilitar a los desempleados unas prestaciones de desempleo adecuadas y de duración razonable (se prevé la relajación temporal de los requisitos de admisibilidad, y una ampliación de la duración de las prestaciones por desempleo para mitigar el impacto de la COVID-19), que no desincentiven un retorno rápido al trabajo, y acompańadas de políticas activas del mercado de trabajo (Orientación n. ${ }^{\circ}$ 7). Y como orientación n. ${ }^{\circ} 8$, los Estados miembros deben desarrollar e integrar una inclusión activa en tres aspectos: con un apoyo a la renta adecuado, unos mercados de trabajo inclusivos (recordemos el acuerdo marco europeo sobre esta materia del año 2010), y desde el acceso a servicios de capacitación de calidad que respondan a las necesidades individuales.

El Consejo indicó a España en su Recomendación n.o 2 que debía respaldar el empleo mediante medidas encaminadas a preservar los puestos de trabajo, incentivos eficaces a la contratación y el desarrollo de las cualificaciones que contemplen el acceso al aprendizaje digital. Por otro lado, habrá que reforzar la protección por desempleo, especialmente para los trabajadores atípicos (atentos a la definición tan amplia que sigue la $\mathrm{OIT}^{24}$ ); y mejorar la cobertura y la adecuación de los regímenes de renta mínima ${ }^{25}$. Como sabemos, el Programa Nacional de Reformas del Reino de España del año en curso y la Estrategia Española de Activación para el Empleo en vigor en cada período, son los instrumentos encargados de trasladar a nuestro mercado de trabajo español y diseñar las vías de cumplimiento de dichas orientaciones generales en política de empleo.

No cabe duda que el papel del diálogo social, en todos los niveles territoriales, es crucial. La Confederación Europea de Sindicatos (CES) identifica iniciativas emblemáticas, que deben ser objeto de un seguimiento inmediato:

desarrollar un enfoque común de las políticas activas del mercado de trabajo, basándose en la experiencia de SURE y diseñando mecanismos permanentes de estabilización y reaseguro de la UE del gasto público en empleo, la protección social y las prestaciones por desempleo ${ }^{26}$.

24 «Formas atípicas de empleo», en https://www.ilo.org/global/topics/non-standard-employment/lang--es/index.htm (acceso a 2/11/2021).

25 «CONSEJO, «Recomendación sobre el Programa Nacional de Reformas de 2020 de España y por la que se emite un dictamen del Consejo sobre el Programa de Estabilidad de 2020 de España", Bruselas, 20.5.2020 COM (2020) 509 final.

26 ETUC, «Prioridades de la CES para el Plan de Acción de Implementación del Pilar Europeo de Derechos Sociales», punto V, febrero 2021. Sobre el «Instrumento europeo de apoyo temporal para mitigar los riesgos de desempleo en una emergencia” (SURE), véase https:/ec.europa.eu/info/ business-economy-euro/economic-and-fiscal-policy-coordination/financial-assistance-eu/fundingmechanisms-and-facilities/sure_es(acceso a 2/11/2021). 
Por último, para finalizar con los fundamentos jurídicos, en este caso desde el ámbito internacional, ya hemos invocado el Programa de "Trabajo decente» de la OIT como fundamento de la protección jurídica por desempleo, complementado en la actualidad con la Agenda 2030 de la ONU, en respuesta a los siguientes objetivos de desarrollo sostenible: 1 . poner fin a la pobreza, 4 educación de calidad inclusiva y equitativa, oportunidades de aprendizaje permanente para todos, 5. igualdad entre géneros, 8. trabajo decente para todos, 10. reducir la desigualdad ${ }^{27}$.

La aplicación del art. 2, d) TRLE, que configura como objetivo de política de empleo «asegurar políticas adecuadas de integración laboral dirigidas a aquellos colectivos que presenten mayores dificultades de inserción laboral», se realizará a través del RD 818/2021, de 28 septiembre, por el que se regulan los programas comunes de activación para el empleo del Sistema Nacional de Empleo, que dedica especial atención a los colectivos vulnerables en tanto que destinatarios de dichos programas, y de los previstos en las CC.AA.

\subsection{La reformulación de los programas comunes de activación para el empleo}

El RD 818/2021 y su regulación de los programas comunes de activación para el empleo del Sistema Nacional de Empleo constituye el nuevo marco "combinado" sobre el que se desarrollan las PAE en todo el territorio del Estado (dando cumplimiento al art. 38 TRLE), a través del SEPE y de las Comunidades Autónomas (como enlace con las Entidades Locales), según su ámbito de competencias, como norma de colaboración y coordinación con ellas, resultante del acuerdo y reconocedora del éxito de algunas de las iniciativas autonómicas que han sido incorporadas a la norma, como buenas prácticas, y dotadas de carácter general (Preámbulo, pág. 7).

27 OIT, «El mundo necesita OIT: El mundo necesita un acelerador mundial para el empleo y la protección social», https://www.ilo.org/global/about-the-ilo/newsroom/news/WCMS_822797/lang-es/index.htm (acceso a 18/10/2021): consiste en un programa que aumentaría las inversiones en protección social universal, trabajo decente y una transición justa y ecológica; que nace en respuesta a que la pandemia ha sido especialmente devastadora para los más vulnerables, sobre todo para las mujeres, los trabajadores de la economía informal y los nińos, y en atención a que se enfrentan a un futuro muy diferente dependiendo de donde vivan. En la misma línea, en el marco del Plan de Acción del Pilar Europeo de Derechos Sociales, el «Mecanismo Social de Alerta o Social Imbalance Procedure» (SIP), que están impulsando España y Bélgica como instrumento para corregir desequilibrios sociales, consiste en establecer una serie de indicadores que los detecte, y sitúa los indicadores sociales al mismo nivel que los macroeconómicos, especialmente si «se aspira a una Europa ambiciosa en derechos, que sea socialmente fuerte, con una economía firme e inclusiva», según la Ministra de Trabajo y Economía Social, https:/www.lamoncloa.gob.es/serviciosdeprensa/notasprensa/trabajo14/ Paginas/2021/020921-mecanismoalerta.aspx; «Yolanda Díaz presenta en Luxemburgo el Mecanismo Social de Alerta", https://elderecho.com/yolanda-diaz-presenta-en-luxemburgo-el-mecanismo-socialde-alerta?utm_medium=email\&utm_source=newsletter\&utm_campaign=20211018_Nwl (acceso a $18 / 10 / 2021)$. 
Nada más empezar su Preámbulo destaca su primera fortaleza, e indica que regula "de modo integral y sistematizado» los programas comunes, estableciendo cuáles han de ser sus contenidos esenciales (el objeto y los contenidos mínimos previstos en cada uno de ellos, las personas destinatarias finales, la financiación y los requisitos específicos y prioridades, art. 1.2). Al comienzo de su articulado destaca su segunda virtud, en el 1.1 al definir su objeto: además de "determinar» dichos aspectos esenciales en los programas comunes, establecer las cuantías de referencia de las subvenciones.

Se autodefine como "texto unitario y global», que "compila, integra y actualiza la normativa hasta ahora dispersa" (tal y como se pone de manifiesto, a modo de ejemplo, en la disposición derogatoria única). Con dicho tratamiento conjunto y de sistematización, se mejora la seguridad jurídica y la transparencia en la aplicación de una normativa muy compleja. Ha venido a paliar, en parte, esa complejidad predicable acerca de la normativa de fomento del empleo, que derivaba de la técnica, continuamente usada en política de empleo, de la yuxtaposición de medidas y reformas, con la impresión cierta de sin hilo conductor claro, que genera un desconcierto en los operadores jurídicos, y haciendo tedioso a los investigadores el estudio en Derecho del Empleo (Costa, 2019: 107 e Illanes, 2020: 77).

Los programas se estructuran en seis secciones coincidentes con los seis ejes en que se ordenan las políticas de activación en dichos instrumentos. Los diecisiete programas comunes son:

- Eje 1 "Orientación», tres programas comunes: el programa de orientación profesional para el empleo y el autoempleo; el de colaboración para las actividades de prospección empresarial e intermediación laboral; y el de proyectos integrales de empleo.

—Eje 2 «Formación», los programas públicos mixtos de empleo-formación $y$, específicamente, los programas experienciales de empleo-formación. Se complementa con los programas de formación profesional para el empleo regulados en el Real Decreto 694/2017, de 3 de julio, por el que se desarrolla la Ley 30/2015, de 9 de septiembre, por la que se regula el Sistema de Formación Profesional para el Empleo en el ámbito laboral.

—Eje 3 «Oportunidades de Empleo»: el programa de inserción laboral a través de obras o servicios de interés general y social, el que persigue tanto la inserción como la inclusión laboral de personas con discapacidad en el mercado de trabajo ordinario y protegido, respectivamente, el programa de integración laboral de personas en riesgo o situación de exclusión social y el dirigido a apoyar la movilidad geográfica.

— Eje 4 "Igualdad en el empleo», tres programas: el programa para la igualdad entre hombres y mujeres, el de inserción sociolaboral para mujeres víctimas de violencia de género, y el dirigido a evitar la discriminación por razón de edad. 
—Eje 5 «Emprendimiento», tres programas: el de fomento del empleo autónomo; el de apoyo a la creación y al empleo en cooperativas y sociedades laborales; y el programa para el fomento territorial del empleo.

-Eje 6 «Mejora del marco institucional», Programa común de Orientación, Emprendimiento e Innovación para el Empleo, que cada servicio público de empleo podrá desarrollar en su respectivo ámbito de actuación.

Nos hemos referido en páginas precedentes a los beneficiarios de estos programas comunes, definidos en su art. 3 con carácter general como personas desempleadas u ocupadas, en cualquier caso, inscritas como demandantes de empleo en los Servicios Públicos de Empleo; de forma más concreta, personas de los colectivos prioritarios por su pertenencia a los vulnerables, como las beneficiarias de prestaciones por desempleo o personas jóvenes inscritas en el Sistema Nacional de Garantía Juvenil, conformando una actualización y ampliación de los colectivos prioritarios de la Ley de Empleo; porque aunque en su art. 4.1 remite, al art. 30.1 TRLE, introduce modificaciones relevantes dentro de una lista que sigue siendo abierta: añade a las personas «en riesgo de caer en desempleo de larga duración», remarcando el enfoque preventivo 28 "de manera preferente» frente al desempleo (que guía a su vez a Planes como REINCORPORA-T), a la mujeres víctimas de violencia de género o de trata de seres humanos, en relación a las personas desempleadas con responsabilidades familiares señala «en el caso de que el servicio público de empleo competente disponga de información».

En cualquier caso, en la determinación de los colectivos, no olvidemos el papel tan relevante que tienen al respecto la antes denominada Estrategia Española de Activación para el Empleo (EEAE), ahora Estrategia Española de Apoyo Activo al Empleo 2021-2024, y en el Plan Anual de Política de Empleo (PAPE), tal y como el RD señala en sus arts. 4.1 y 13, que fijarán las prioridades del momento, y en atención a las peculiaridades de las CC.AA., siempre en el marco general de la Cartera Común de Servicios del Sistema Nacional de Empleo ${ }^{29}$. De este modo se iban adecuando temporalmente al marco en vigor, puesto que muchas de las normas reguladoras de los programas comunes eran anteriores incluso al traspaso de competencias a las CC.AA.

Sin pretender realizar una exposición exhaustiva de todos los programas comunes, numerosos y con múltiples aspectos, centrándonos en aquellos en los que los colectivos prioritarios son los destinatarios últimos, en consonancia con el objeto de este estudio, en primer lugar, hemos de mencionar que en la sección $3 .^{a}$ sobre "Oportunidades de Empleo», se prevé el «Programa de integra-

28 La Ley de Empleo, desde su primera versión en 2003, hasta la modificación de 12/02/2011, contenía un art. 24 que llevaba por título «el enfoque preventivo de las políticas activas de empleo».

29 Real Decreto 7/2015, de 16 de enero (BOE n.o 31, de 5 de febrero). 
ción laboral de personas en riesgo o situación de exclusión social» (arts. 58 y ss. $\mathrm{RD})$.

Se trata de un programa en el que es de destacar la variedad de colectivos a los que va dirigido y, especialmente, entre los que figuran personas que únicamente son expresamente mencionadas en este programa, tales como las personas en desempleo de "muy» larga duración, las minorías étnicas, las personas trans, y las personas con responsabilidades familiares no compartidas (lo que por supuesto no impide que sean beneficiarios de otros programas); siempre con la cláusula de apertura a cualquier colectivo, esto es, que la Administración Pública competente considere inmerso en dicha situación, que se repite asimismo en los demás programas.

El vehículo para intentar alcanzar dicha integración laboral no puede ser más que un itinerario personalizado de inserción protagonizado, no solo por los profesionales de apoyo/orientadores de los servicios de empleo, sino por las entidades o personas trabajadoras autónomas que los contraten: empresas de inserción, asociaciones, empresas y entidades sin ánimo de lucro. Las medidas pueden consistir en una subvención de 1.000 euros por participante, con una duración de seis meses y con un máximo de 15 participantes por itinerario, o de 12.120 euros por puesto de inserción creado o mantenido durante doce meses. Sin embargo, no se limita a fomentar su empleo en este tipo de empresas de tránsito, sino que se incluye la previsión de incentivos por la contratación de participantes en el itinerario en el mercado de trabajo ordinario (art. 60, d RD, cuantía en art. 64), que se incrementarán en 500 euros si la contratada es una mujer.

Parece que el recurso a los incentivos no resulta la más eficiente de las políticas porque los empresarios no los utilizan con frecuencia, debido al temor a las comprobaciones sobre su correcta aplicación, realizadas por la Inspección de Trabajo y Seguridad Social (Álvarez Cortés, 2019: 248). Es por ello que desde la doctrina se venía pidiendo la reorientación del gasto desde los incentivos a la formación (Pérez del Prado, 2017: 238).

En cualquier caso, y es extrapolable a cualquier programa, la génesis del éxito en la ejecución de los mismos, consideramos que deriva de un buen estudio personalizado de caso, a lo que ha de seguir el compromiso firme de la persona desempleada-participante; la clave radica en que del acuerdo personal de empleo (art. 29.2 TRLE) derive un itinerario pactado, que implique al actor en la consecución de los objetivos del programa diseńado para la consecución de un puesto de trabajo ((Pérez del Prado, 2017: 277).

Lo dicho anteriormente conecta con otro programa: «Proyectos integrales de empleo» (art. 24 RD) ${ }^{30}$, dirigido preferentemente a personas beneficia-

30 Pueden partir de la iniciativa privada, como contempla la Disposición Adicional 13. ${ }^{\text {. }}$ 
rias de prestaciones o subsidios de desempleo, de la RAI o del IMV (al menos en un $40 \%$ de los participantes). Los instrumentos para conseguir la integración social son: «itinerarios personalizados que comprendan acciones de información, orientación, asistencia, asesoramiento, formación, práctica laboral y, en su caso, movilidad geográfica para la búsqueda de empleo y fortalecimiento de las habilidades sociales» (art. 24.1 RD). Actúa como criterio de selección, la adecuación a las características del programa y la pertenencia a los colectivos prioritarios del art. 4.1 RD, ampliable por la Administración Pública si fuera necesario.

Otro aspecto relevante es que el RD 818/2021 contiene una derogación que ha de ser mencionada específicamente: la de los "contratos» de colaboración social, que venían siendo regulados por los arts. 272.2 TRLGSS y el RD 1445/1982, por el que se regulan diversas medidas de fomento del empleo. Han pasado a ser sustituidos por el «Programa de inserción laboral a través de obras los servicios de interés general y social». Para empezar, resulta loable que deje de hablarse de "trabajos o contratos de colaboración social» cuando no implicaban relación laboral alguna; en segundo lugar, había que finalmente atender a la jurisprudencia derivada del uso abusivo que de la figura se ha hecho en la Administración. Para ser beneficiario del nuevo programa, bastará con que se trate de una persona desempleada u ocupada, registrada como demandante de empleo y servicios en los mismos (art. 3.1 RD), y el supuesto sí consistirá en la contratación de la persona, para la realización de dicho tipo de obras (art. 41 $\mathrm{RD}$, objeto). El propio RD incorpora los criterios de prioridad en la selección (art. 45): adecuación de la cualificación al puesto ofertado, favoreciendo la primera experiencia profesional (jóvenes), y personas pertenecientes a los colectivos prioritarios del art. 4.1. (remisión a los del 30 TRLE, pero con preferencia a los desempleados de larga duración y a los colectivos con mayores dificultades de integración laboral: personas con discapacidad, en riesgo de caer en desempleo de larga duración, mujeres víctimas de violencia de género y de trata de seres humanos, en exclusión social, con responsabilidades familiares, inmigrantes), siempre con la cláusula de apertura en vigor.

Por otra parte, y siendo un programa que no actúa directamente sobre los colectivos vulnerables pero que sí que su mejora es el fin último, en el «Programa de colaboración para las actividades de prospección empresarial e intermediación laboral», dentro del Eje 1 sobre «Orientación», que parte de la colaboración público-privada o público-pública, se prevé el abono de un incentivo por inserción laboral conseguida a través de agencias o entidades colaboradoras (2.500 euros), en función de la edad y tiempo de inscripción como demandante de empleo y servicios, y del colectivo al que pertenezca la persona (art. 23.2, a $\mathrm{RD})$. Vemos que este supuesto se focaliza en una combinación de variables-factores de vulnerabilidad, como tiempo en desempleo + la edad + pertenencia a colectivo prioritario, en consonancia a su vez con las necesidades de cobertura 
de puestos de trabajo y de nuevos perfiles planteados por las empresas y/o sectores de actividad (punto 1 del citado artículo).

La mujer figura como destinataria de numerosos programas: el enfocado a la igualdad entre hombres y mujeres, en el que se incentiva su contratación indefinida y su participación en acciones de orientación o mejora de su empleabilidad, con un programa específico si es víctima de violencia de género; es mencionada en el de integración laboral de personas en riesgo o situación de exclusión social, con aumento del incentivo económico; se prevén incentivos para la promoción de la presencia femenina en las ocupaciones y sectores en los que se encuentran infrarrepresentadas; para el fomento del empleo de calidad de las mujeres, el art. 70 establece que los programas o acciones de orientación o mejora de la empleabilidad estarán ocupados, al menos al $50 \%$, por mujeres, etc.

Por último, en esta exposición que pretende destacar las cuestiones relevantes sobre las que incide el RD, la Disposición Adicional 3.a , en su punto 3, atribuye al Servicio Público de Empleo competente en la gestión del programa, el seguimiento de la participación en el mismo de las personas beneficiarias de prestaciones por desempleo, y la evaluación de los resultados obtenidos, que se grabarán en el Sis6ktema de Información de los Servicios Públicos de Empleo (SISPE).

En la nueva Estrategia Española de Apoyo Activo al Empleo 2021-2024, como marco normativo para la coordinación y ejecución de las políticas activas de empleo e intermediación laboral en el conjunto del Estado, la evaluación se concibe como un eje vertebral, a través de un modelo integrado de seguimiento orientado hacia resultados, transparente y accesible (en cumplimiento del art. 39 TRLE). En concreto, estos son los cinco objetivos estratégicos que se han formulado: el enfoque centrado en las personas y en las empresas, la coherencia con la transformación productiva, la orientación hacia resultados, la mejora de las capacidades de los Servicios Públicos de Empleo, y la gobernanza y cohesión del Sistema Nacional de Empleo ${ }^{31}$. Y es que "con datos suficientes, cualquier intervención pública es evaluable, desde el impacto de un programa de empleo para determinado colectivo hasta una estrategia de lucha contra la pobreza» (De la Rica, 2021: 6).

La forma de ejecutar el control es a través de indicadores de seguimiento, como los relativos a los créditos destinados a formación, que serán objeto de un seguimiento semestral a través de un informe específico de nueva implantación. De manera general, se establecen indicadores de impacto para todos los fondos

31 «La calidad de las estrategias de empleo requiere un compromiso firme con la evaluación de los programas», "Yolanda Díaz plantea estrategias de empleo de calidad para salir de la crisis y avanzar hacia una Europa más social», https://prensa.mites.gob.es/WebPrensa/noticias/ministro/ detalle/3947 (acceso a 26/02/2021). 
de todos los ejes para verificar a los 6,12 y 18 meses la empleabilidad de las personas beneficiarias. En una noticia del Ministerio de Trabajo y Economía Social se indicaba que estos instrumentos se fijarán en el PAPE 2021 y en la orden ministerial de distribución de fondos ${ }^{32}$.

A continuación, se trata de actuar con los resultados positivos obtenidos, a ser empleados en la repetición de actuaciones y políticas. Es por ello que se requieren estudios sobre experiencias prácticas reales desarrolladas con colectivos concretos; por ejemplo, el realizado sobre el de mayores de 40 años que, en Andalucía, según datos de junio de 2018 del Observatorio Argos de la Consejería de Empleo, Empresa y Comercio de la Junta de Andalucía, eran más del 50\% de las personas desempleadas. Consistió en analizar una experiencia concreta de inclusión sociolaboral, de 43 personas de dicha franja de edad, con la finalidad de generar una buena práctica de inclusión (García Aguilera, 2020: 9).

\section{Sobre el Plan REINCORPORA-T}

Cuanto más largo es el período en el que una persona se encuentra en desempleo, menores son sus posibilidades de vuelta al mercado de trabajo, y mayores las probabilidades de cronificación de dicha situación. A ello se suma que, si han pasado dos años, las prestaciones de desempleo se habrán agotado y, de poder demostrar que se está siguiendo una búsqueda activa de empleo, se estará a los programas extraordinarios de desempleo y a la solicitud del IMV: la ausencia de ingresos para el desarrollo de la vida diaria, implica pobreza y un claro riesgo de exclusión social.

De acuerdo con la EEAE del período 2017-202033, marco en el que se inserta este Plan trienal para prevenir y reducir el Desempleo de Larga Duración para el período 2019-2021, los servicios y programas que desarrollen los Servicios Públicos de Empleo deberán dirigirse al cumplimiento de cinco objetivos estratégicos, entre los que destaca

potenciar el empleo como principal instrumento de inclusión social, mejorando de manera prioritaria la activación e inserción de personas desempleadas de larga duración y de las mayores de 45 años mediante instrumentos como el Plan de Empleo para personas paradas de larga duración (objetivo B).

32 https://prensa.mites.gob.es/WebPrensa/noticias/ministro/detalle/3982 (acceso a 30/10/2021).

33 En septiembre se celebró una primera Mesa de Diálogo Social en la que se ha tratado el inicio de la labor de los Grupos de Trabajo para la elaboración de la Estrategia Española de Activación para el Empleo 2020-2024, «El Ministerio de Trabajo y Economía Social se reúne con los agentes sociales para abordar el futuro de las Políticas Activas de Empleo", http://prensa.mites.gob.es/WebPrensa/ noticias/laboral/detalle/3883 (acceso a 18/09/2020). 
Se encuentra en su última fase de ejecución y, desde su punto 1 , se refiere al «compromiso» con las personas paradas de larga duración «y otras personas especialmente vulnerables ante el empleo», con un ámbito subjetivo de aplicación bien amplio como personas vulnerables hay, que repara incluso en los trabajadores pobres, a los que el Plan alude en varias ocasiones al referirse a «la pobreza laboral o la pobreza en el trabajo» (Carril, 2021: 83), y con un enfoque preventivo que se refleja claramente cuando prevé como destinatarias a las personas incursas en un proceso colectivo de regulación de empleo.

En cualquier caso, este Plan que implica el compromiso mencionado, asumido en un período de recuperación económica, no coincidente con características del período de ejecución, tratándose de un desajuste importante, si bien las actuaciones que promociona el Plan figuran condicionadas a la existencia de financiación para su ejecución (punto 7 sobre impacto presupuestario), habiendo sido presentado en el Programa Nacional de Reformas 2020 (pág. 70) como un Plan dotado con un presupuesto de 4.000 millones de euros ${ }^{34}$.

Por su parte el PAPE 202035, lo menciona en su objetivo estratégico C, sobre "potenciar el empleo como principal instrumento de inclusión social, mejorando de manera prioritaria la activación e inserción de los colectivos más vulnerables, con especial atención a las personas que hayan perdido su empleo como consecuencia del COVID-19, personas desempleadas de larga duración y las mayores de 45 años»; y lo incardina en el Eje 6 sobre «mejora del marco institucional del Sistema Nacional de Empleo». Señalaba su carácter de urgencia, y lo definía como Programa de impacto - con carácter integral y con una mayor eficiencia del gasto público-, que pone en marcha medidas específicas y coordinadas.

Estando en ejecución el Plan, surge la pandemia COVID-19, que implica un empeoramiento de la situación de los PLD o un mayor riesgo de incurrir en tal condición, por lo que son necesarias nuevas medidas, acciones formativas, para evitar que el desempleo se haga crónico, en especial en relación a las personas mayores de 45 años que recaigan en una situación de desempleo, y las que se sometan a ERTES.

34 Aprobado en Consejo de Ministros 5/04/19. Fácil acceso a los PNR en https://www.hacienda.gob.es/es-ES/CDI/Paginas/EstrategiaPoliticaFiscal/ProgramaNacionalReformas.aspx

35 Resolución de 26 de octubre de 2020, de la Secretaría de Estado de Empleo y Economía Social, por la que se publica el Acuerdo de Consejo de Ministros de 20 de octubre de 2020, por el que se aprueba el Plan Anual de Política de Empleo para 2020, según lo establecido en el artículo 11.2 del texto refundido de la Ley de Empleo, aprobado por el Real Decreto Legislativo 3/2015, de 23 de octubre (BOE n. ${ }^{\circ} 289$, de 2 de noviembre). De los Servicios y programas por eje y CC.AA., como Eje 1 «Orientación», lo incorpora Galicia; en el Eje 5 «Emprendimiento», Castilla y León; para Andalucía, Aragón, Asturias, Baleares, Canarias, Cantabria, Castilla La Mancha, Castilla León, Cataluña, Valencia, Extremadura, Galicia, Madrid, Murcia, Navarra y La Rioja en el Eje 6 sobre "Mejora del marco institucional del Sistema Nacional de Empleo» (anexo III PAPE 2020). 
En cualquier caso, este Plan específico de fomento del empleo es exhaustivo en la exposición de las medidas, siguiendo la dinámica de presentación de una clasificación de las de política activa de empleo según los Ejes de actuación: En relación al Eje 1 sobre orientación, prevé la contratación de profesionales de referencia que desempeñen su labor en puntos únicos de atención. En cuanto al 2 formación, ha de ser permanente, en sectores de interés preferente e interés público. Sobre el Eje 3, oportunidades de empleo, insiste en los colectivos vulnerables como destinatarios, en personas del medio rural, en servicios de cuidado. También en el establecimiento de límites a la temporalidad, incentivando la contratación indefinida. En el Eje 4, sobre la igualdad de oportunidades en el acceso al empleo, insiste en la situación de la mujer, específicamente en el ámbito rural, y en servicios cuidados. Se centra en la economía social, local, rural, en relación al Eje 5, emprendimiento, y en el Eje 6, sobre la mejora del marco institucional, se refiere a los recursos humanos, en la contratación de 3000 nuevos orientadores como personal técnico de acompañamiento, y desde la innovación en dicho proceso, que parta del estudio de trayectorias profesionales. El objetivo es alcanzar la ratio de 1 orientador por cada 100 desempleados, y que se trate de personal especializado que trabaje en colaboración con todos los implicados (interlocutores sociales, Inspectores de Trabajo y Seguridad Social).

Nos centramos en una de las medidas, la relativa a la mejora cuantitativa y cualitativa en el servicio de orientación profesional, y en uno de los colectivos, los adultos más vulnerables, que suelen ser los que menos apoyo reciben. Fijémonos en la importancia de la edad en la selección de los trabajadores afectados por un despido colectivo, dada la situación del colectivo de mayores de 55 años, con una edad general de jubilación más tardía, sin posibilidades de pre-jubilación en la mayoría de los casos, y las dificultades que tendrán para adaptarse a nuevas formas de trabajo en entornos digitales (Castellano Burguillo, 2017: 264). Se encuentran entre los colectivos vulnerables mencionados en el art. 51.5 TRET, que gozan de protección en caso de despido colectivo:

Mediante convenio colectivo o acuerdo alcanzado durante el periodo de consultas se podrán establecer prioridades de permanencia a favor de otros colectivos, tales como trabajadores con cargas familiares, mayores de determinada edad o personas con discapacidad.

Los adultos que trabajan de manera informal, incluidas las personas trabajadoras domésticas, en general encuentran mayores dificultades para acceder a la información y el apoyo necesarios para transitar hacia un trabajo decente. Si bien los servicios de orientación profesional digitales se han ampliado, la experiencia muestra que los grupos más vulnerables tienen mayores dificultades para acceder a equipos digitales e internet $\mathrm{y}$, a menudo, carecen de las competencias necesarias para beneficiarse de los servicios digitales. Para la OIT «una orientación profesional eficaz empodera a las personas» al abordar directamente las ne- 
cesidades de las poblaciones vulnerables que enfrentan diferentes formas de desventaja social, y ayuda a compensar este acceso limitado a la información y el apoyo necesarios a través de las redes sociales. Hay buenas razones para entender por qué ciertos grupos, como los inmigrantes, las minorías étnicas, las poblaciones rurales, las personas mayores, los trabajadores de sectores informales, las personas con discapacidad, los trabajadores poco cualificados, los ciudadanos con un estatus socioeconómico bajo, así como los desempleados, se enfrentan a barreras adicionales a la hora de visualizar y planificar sus carreras. En consecuencia, una orientación profesional eficaz hace uso de una serie de enfoques para lograr ser pertinente, adecuada y accesible a diferentes personas con diferentes necesidades, entre otros, a través de actividades de difusión ${ }^{36}$.

Del necesario ensamblaje entre el Plan estatal con los ámbitos regionales derivan efectos a nivel autonómico, como en el caso de la Comunidad Autónoma Andaluza, en el Acuerdo de 5 de mayo de 2020, del Consejo de Gobierno, por el que se aprueba el Contrato Plurianual de Gestión de la Agencia Servicio Andaluz de Empleo para el periodo 2020-2021, que seńala que

la aprobación del Plan de choque por el empleo joven 2019-2021 y el Plan Reincorpora-T 2019-2021, aportan novedades en el ámbito de la gestión (como la incorporación de nuevo personal orientador) van a afectar a la configuración del Contrato». Se la dota de una nueva estructuración, que refuerza sus principales líneas de acción, entre las que señala la «atención especial a colectivos prioritarios, tales como: jóvenes, personas mayores de 45 ańos, personas con discapacidad, personas en situación de riesgo y/o exclusión social, mujeres víctimas de violencia de género. Para ello se pondrán en valor los Planes que ya se han definido para algunos de ellos ${ }^{37}$.

En el mismo sentido expuesto de la coordinación entre plano estatal y autonómico, y no habiendo sido localizados los informes de la Comisión de Seguimiento del Plan (composición en punto 9 Plan), cuya primera evaluación global debió realizarse en abril de 2020, a los doce meses de ejecución, coincidiendo con la situación de estado de alarma, sin embargo nos hemos tropezado con la respuesta del Gobierno a una pregunta formulada al Congreso sobre el Plan de Choque por el Empleo Joven 2019-2021, precisamente en dicha fecha ${ }^{38}$, que nos parece puede ser extrapolada al análisis de nuestro Plan objeto de estudio porque trata de la cuestión de la contratación por parte del Gobierno de orientadores y mediadores para el Plan. Se responde en el sentido de que no corresponde al Gobierno realizar contratación alguna. De acuerdo con las previsiones

36 OIT, «Invertir en la orientación profesional», 2021, pág. 13, https://www.ilo.org/wcmsp5/ groups/public/---ed_emp/---ifp_skills/documents/publication/wcms_821112.pdf (acceso a 17/10/2021).

37 BOJA n.o 89, de 12 de mayo, https://www.juntadeandalucia.es/boja/2020/89/3 (acceso a 19/10/2021).

38 https://www.congreso.es/entradap/l14p/e2/e_0024614_n_000.pdf (acceso a 19/19/2021). 
del Plan, cada Comunidad Autónoma realizará las incorporaciones de personal que le correspondan, según la normativa aplicable en materia de función pública. Se añade que para el seguimiento del Plan de Choque se cuenta con la ayuda del Servicio de Apoyo a las Reformas Estructurales de la Comisión Europea (SSRS). Se instrumenta a través de su Programa de Apoyo a tales reformas, que se ha traducido en una asistencia de apoyo técnico proporcionada al SEPE por el Banco Mundial para el seguimiento del Plan, mediante su colaboración en la elaboración de informes territoriales de cada Comunidad Autónoma, individualizados, en los que se ha recabado información sobre las incorporaciones de personal de orientación por Comunidad Autónoma, en ejecución de la primera medida del Plan. En cuanto al seguimiento de las tareas de orientación y de prospección de los orientadores del Plan, se señala que se estaban poniendo en marcha los mecanismos necesarios en el seno del Sistema de Información de los Servicios Públicos de Empleo (SISPE) para poder disponer de información para la trazabilidad de las actuaciones de orientación. Respecto a las actuaciones de prospección, está previsto desarrollar un instrumento que permita recabar la información sobre las que se realicen. Finalmente se destaca que «la actividad de seguimiento del Plan de Choque es incipiente y compleja, puesto que implica a una gran pluralidad de sujetos y muy distintos tipos de acciones».

La Comisión de Seguimiento del Plan ha tenido que comprobar los siguientes parámetros: la inspección del nivel de ejecución y cumplimiento de los objetivos; el seguimiento de la periodicidad de las reuniones trimestralmente, pudiendo decidir correcciones en coherencia con los objetivos marcados; la supervisión y control de las medidas fijadas, así como también de los resultados alcanzados; los medios e instrumentos necesarios (recursos probabilísticos y de gestión) para conocer el avance y el impacto de las diferentes medidas.

Como ejemplos de medidas, incorpora cláusulas de carácter social en los contratos del sector público que garanticen la contratación de los desempleados PLD de 45 o más años en sus proyectos e iniciativas (entre un 5-10\%); la contratación en Centros Especiales de Empleo y empresas de inserción, la bonificación mensual de la cuota empresarial a la Seguridad Social por contratación laboral indefinida, incentivos fiscales, reducción o bonificaciones de cuota, para el autoempleo, el mantenimiento de la inscripción y en el itinerario personalizado de inserción (IPE) de los «en riesgo de inactivos» así como su captación, y el establecimiento de puntos únicos de atención desde la coordinación entre los SPEs y los Servicios Sociales.

$\mathrm{Si}$ atendemos a los datos del Informe trimestral de análisis del mercado de trabajo de septiembre $2021^{39}$, el desempleo de larga duración ha evolucionado

39 El paro registrado, SEPE, al terminar el mes de septiembre de 2021 era de 3.257 .802 personas, 76.113 parados menos que en agosto, un 2,3\% de descenso. El descenso mensual es gene- 
favorablemente, hasta el segundo trimestre de 2020, acumulando descensos sucesivos, tanto si se atiende al tiempo que llevan en paro, de acuerdo con el criterio de EUROSTAT que es el utilizado en el ámbito de la UE, como si se atiende al tiempo que llevan buscando un empleo, de acuerdo con los datos publicados por el INE. A partir del tercer trimestre, sin embargo, está aumentando. En cuanto a su incidencia, en el primer trimestre de 2021, último dato disponible a nivel EUROSTAT, afecta al 39,2\% del total de parados, 4,1 puntos por encima de la alcanzada hace un año. La tasa de PLD, por su parte, se sitúa en un nivel superior al alcanzado hace un año, en el 6,3\% de la población activa, 2,1 puntos más elevada. La incidencia del PLD sube al 30,5\%.

Por último, el PNR 2021 no menciona el Plan REINCORPORA-T. Solo al tratar las políticas de empleo, señala que se han desarrollado planes de apoyo a parados de larga duración, por ejemplo, en Navarra, a través del Plan de activación laboral para mayores de 45 años, y en el País Vasco mediante el Programa de ayudas a la contratación de personas desempleadas mayores de 30 años en situación de desempleo de larga duración. (pág. 111). Por otro lado, se refiere al Plan de Recuperación que, en relación al mercado de trabajo, prevé un programa coherente de reformas que tiene por objeto reducir la temporalidad, el desempleo estructural y el desempleo juvenil hasta llegar a la media europea, mediante un nuevo modelo laboral que describe en su pág. 23. Respecto de la Recomendación 2, prevé que se adoptarán reformas para mejorar el funcionamiento del mercado de trabajo, corrigiendo los problemas estructurales de dualidad, precariedad, las elevadas tasas de desempleo — especialmente en algunos colectivos- Se otorga un papel fundamental al Ingreso Mínimo Vital, que modernizará los mecanismos de redistribución social, al tiempo que su articulación con las políticas de inserción laboral servirá para lograr un mercado de trabajo más inclusivo (pág. 38).

\section{Conclusiones}

La creación de trabajo decente, en cumplimiento de la Agenda de la OIT, de los Objetivos de Desarrollo Sostenible 2030 de la ONU, y para garantizar el derecho al trabajo reconocido en el art. 35 de la Constitución Española, avalan la aprobación de Planes como REINCORPORA-T, cuyo objetivo de fondo es contrarrestar los factores de vulnerabilidad que condicionan a individuos y gru-

ralizado, en hombres y mujeres, en adultos, en todos los sectores de la economía y en doce Comunidades Autónomas. En términos anuales, asimismo, desciende en todos los colectivos, con mayor intensidad en hombres, en adultos, en servicios y en las Comunidades Autónomas de Andalucía y Cataluña.https://www.mites.gob.es/ficheros/ministerio/sec_trabajo/analisis_mercado_trabajo/ numeros/138/138.pdf (acceso a 20/10/2021). 
pos, dificultando su acceso al mercado de trabajo ordinario. La política de empleo «centrada en las personas», en cada ciudadano, para paliar sus carencias y atender a sus necesidades, en especial de los que están en riesgo, ha de ser la génesis de todos los programas, según quienes, en cada período y territorio, hayan de ser los destinatarios prioritarios de las medidas; porque pertenecer a los vulnerables implica riesgo grave de exclusión social. Si se reduce el desempleo de larga duración, se previene su desencadenamiento.

La solución no puede ser el recurso al Ingreso Mínimo Vital, como prestación no contributiva de la Seguridad Social, configurada como un seguro colectivo pensado para personas vulnerables, y formulado para un momento demasiado tardío, como herramienta para individuos ya en exclusión social: revela la ausencia de prevención, en ocasiones el fracaso de la misma, es un paliativo, aunque contemple el diseño de "estratégicas de inclusión» para los beneficiarios, desde la remoción de los obstáculos sociales y laborales (art. 28.1 RD-ley 20/2020, por el que se establece el Ingreso Mínimo Vital ${ }^{40}$ ), a través por ejemplo del programa de proyectos integrales de empleo (art. 25 RD 818/2021, como personas destinatarias), y su carácter prioritario en el diseño de los incentivos a la contratación (art. 28.2).

Por tanto, como primera conclusión, el acento ha de ponerse en las políticas públicas de carácter preventivo. A ello responde la nueva regulación de las políticas activas de empleo, a lo que ha de seguir una gestión eficaz y eficiente de las mismas. El RD 818/2021 sobre programas comunes de activación para el empleo que nace con una función imprescindible: sistematizar. No se pueden reducir las actuaciones porque son muy necesarias, pero sí evitar duplicidades, facilitar su encuadramiento, actualizar los programas, y atacar los problemas en su origen: de nuevo el enfoque preventivo, intentando frenar la materialización de los riesgos.

Como segunda conclusión, la tendencia hacia la ampliación nominativa de colectivos que aplicó el Plan REINCORPORA-T y es seguida en el RD 818/2021, parece que se consolida en el Anteproyecto de Ley de Empleo, aprobado por el Consejo de Ministros el 3 de diciembre de $2021^{41}$, que incluye como nuevos colectivos a personas con capacidad intelectual límite, personas que sufren trastornos del espectro autista, migrantes, beneficiarias y beneficiarios de protección internacional, mujeres víctimas de violencia de género, personas que pertenecen a minorías étnicas o personas trabajadoras que provienen de sectores en reestructuración.

40 BOE n. ${ }^{\circ} 154$, de 1 de junio.

41 «El Gobierno impulsa la transformación total de los servicios públicos de empleo que permitirá un servicio de vanguardia e impulsar la intermediación laboral», https://prensa.mites.gob.es/ WebPrensa/noticias/ministro/detalle/4050 (acceso a 14/12/2021). 
Como tercera conclusión, y basándonos en la reflexión a la que nos ha llevado el estudio del Plan REINCORPORA-T, consideramos que son numerosos y variados los aspectos mejorables en las políticas activas de empleo en favor de la protección del desempleo: en primer lugar, es precisa una mejor difusión de los servicios y programas que se ofertan a la ciudadanía, darles más y mejor publicidad, de forma más cercana y comprensible para los destinatarios.

Por otra parte, en segundo lugar, la clave está en la atención personalizada de calidad, en los servicios de orientación e información a los usuarios, por los agentes de intermediación laboral.

Por ejemplo, en los Itinerarios Individualizados de Inserción o IPEs es importante que sea siempre el mismo agente de empleo/ «orientador de referencia» quien realice la intermediación y oferte las políticas activas de empleo al mismo desempleado, que debe participar en citas frecuentes y a demanda, según sus necesidades en cada momento.

En cualquier caso, es una labor a ser desarrollada por equipos de trabajo multidisciplinares, al servicio de los desempleados; en los que la atención psicológica y las dinámicas de autoayuda en ocasiones habrán de estar presentes; también el fomento de la cooperación e intercambio.

Habría que reducir la burocracia y los tiempos en la atención a los demandantes de empleo. Es por ello que, en tercer lugar, se debe incorporar una serie de rutinas como la atención inmediata a los afectados por un despido colectivo en función de su edad, o cuando se vea afectada una mujer/víctima de violencia de género; seguido del diseño, muy estudiado y adaptado a la persona concreta, del IPE, sellado con la firma del acuerdo personal de empleo previsto en el art. 29.2 TRLE, y de un programa de acompañamiento que ha de estar marcado por la facilitación de las transiciones laborales, y ello, desde la formación para la reconversión.

Y llegamos a la cuarta conclusión, la formación a lo largo de la vida, en consonancia con el envejecimiento activo, es la constante para prevenir el desempleo, de larga duración, y su cronificación. Los cursos de formación para desempleados habrán de atender tanto a la mejora de su cualificación para el mercado de trabajo del momento, como a las necesidades de las empresas del entorno. En estos momentos, volviendo a los colectivos vulnerables de mujeres y trabajadores mayores, es patente la necesaria adquisición de competencias digitales, así como las competencias básicas para quienes presenten déficit de formación, con una especial atención a las personas trabajadoras salientes de ERTEs.

En este sentido, en relación a las personas de edad madura, próxima a la edad de jubilación, no debe minorarse el gasto en políticas activas de empleo para aliviar la transición de etapas; es más, debe aumentarse siempre que asegure su mantenimiento o reinserción laboral. De lo contrario habrá que recurrir a re- 
cursos como el subsidio para mayores de 52 años que no garantiza, debido a su importe, una vida digna.

Otra técnica en favor de la disminución del desempleo de larga duración habrá de ser la reasignación del empleo hacia los sectores y ocupaciones con mayor potencial de crecimiento. Para ello el recurso a la recualificación de los trabajadores, mientras tengan la cobertura económica del desempleo, habría de ser la regla. Y por qué no un proceso de aprendizaje de oficios con demanda en el mercado, ya sea tradicional o digital. La OIT ayuda a compartir experiencias con otros países, y en este sentido nos pone como ejemplo a Austria y Dinamarca, que han tenido éxito con el uso de los sistemas de aprendizaje para combatir el desempleo juvenil ${ }^{42}$.

Por último, nos preguntamos cuál podría ser la contribución de cada uno de los implicados en este marco: las personas que quieran acceder al mercado de trabajo, deben acudir a los agentes de intermediación y seguir fielmente el itinerario personalizado de inserción que les hayan diseñado en atención a sus capacidades y posibilidades. La actitud pro-activación parte de uno mismo. Han de estar comprometidos con su IPE. Por otro lado, en cuanto a los que estén ocupados y quieran mejorar su empleo, bien porque pertenezcan al colectivo de trabajadores pobres o porque su empleo no se corresponde con la cualificación que aporta al mercado de trabajo, de nuevo el recurso a la intermediación laboral y su disposición a una formación a lo largo de la vida o "sistema de formación permanente».

De otro lado, las empresas han de implicarse incorporando medidas de responsabilidad social corporativa que impulsen el desarrollo de acciones de sensibilización y mantenimiento en el empleo de colectivos propensos a caer en situación de PLD: trabajadores maduros, mujeres, tanto más si son de mayor edad, susceptibles de sufrir violencia de género, etc. Deben hacer una puesta en valor de la experiencia profesional que los trabajadores maduros aportan al mercado y a sus compañeros. También ofrecer formación con compromiso de contratación.

Los Servicios Públicos de Empleo, y las entidades colaboradoras en función de la colaboración público-privada en los servicios de la Cartera del Sistema Nacional de Empleo, en materia de intermediación laboral y políticas activas de empleo en particular, tienen múltiples funciones asignadas en la Ley de Empleo, y en la práctica deben abogar por la formación especializada de sus agentes de empleo, el aumento cualitativo y cuantitativo de agentes de empleo/orientadores profesionales.

Como tarea relevante, es preciso que hagan un seguimiento de las personas inactivas y de quienes dejan la inscripción desde situaciones de PLD.

42 «Las pasantías: una buena estrategia contra el desempleo juvenil», https://www.ilo.org/global/ about-the-ilo/activities/event-coverage/WCMS_232445/lang--es/index.htm (acceso a 3/11/2021). 
De la coordinación estrecha entre Servicios Públicos de Empleo y sus entidades colaboradoras, en especial del ámbito local y en la orientación profesional, y los Servicios Sociales en la atención a ciertos colectivos vulnerables, emanarán resultados efectivos y resolutivos.

Insistimos en que es muy necesaria la difusión de los resultados de inserción laboral para PLD, porque si son positivos atraerán a más candidatos; de los negativos, se deduce qué no tiene sentido seguir haciendo. $Y$ en este sentido, debemos poner de manifiesto de nuevo la falta de acceso público a los resultados obtenidos durante la ejecución de Planes como el analizado, lo que dificulta la valoración externa al SEPE y a la Comisión de Seguimiento. Entre los aspectos en los que los Servicios Públicos de Empleo deben mejorar su eficiencia, figura la transparencia, necesaria para los estudiosos del Derecho del Empleo.

Prevención y evaluación son las dos palabras que deben primar en las políticas de empleo, o, en una secuencia más lógica, desde la "evaluación de los resultados» de los programas activos de empleo (arts. 10.5 TRLE y 14.3 $\mathrm{RD} 818 / 2021$ ), se puede deducir el «enfoque preventivo» necesario para avanzar, de forma decidida, en la mejora del acceso al mercado de trabajo «de cada ciudadano» (personalizado, adecuado a la vulnerabilidad que aporte): con un «enfoque centrado en las personas».

\section{Bibliografía}

Aguilar Gonzálvez, M. ${ }^{a}$ Cristina (2019). «El principio de condizionalità y la aplicación efectiva de la coordinación entre políticas activas y pasivas de empleo en Derecho italiano y español», Revista Trabajo y Derecho, n. ${ }^{0} 51$.

Álvarez Cortes, Juan Carlos (2019). «Bonificaciones y reducciones como incentivos a la contratación de las mujeres», en "Estudios sobre la mujer trabajadora y su protección jurídica» (Gómez Salado, Migue Ángel, dir.).

Areta Martínez, María (2010). "Las políticas activas de empleo dirigidas a colectivos vulnerables: las medidas dirigidas a personas con discapacidad, jóvenes y mujeres», en VV.AA. San Martín Mazzucconi, Carolina «La política de empleo como instrumento de inclusión social: un análisis jurídico», Servicio de Publicaciones Universidad Rey Juan Carlos.

Bengoetxea Alkorta, Aitor (2020). «La inclusión socio-laboral de los grupos vulnerables. Colectivos y formas de inclusión a través del trabajo», CIRIEC-España, Revista Jurídica de Economia Social y Cooperativa, n. ${ }^{\circ} 36$.

Carril Vázquez, Xosé Manuel (2021). «Pobres con trabajo: una categoría estadística en la Unión Europea y un colectivo sin entidad jurídica en España, al menos en su Derecho del Trabajo y Seguridad Social», Documentación Laboral, n. ${ }^{\circ} 122$.

Castellano Burguillo, Emilia (2017). «Planes de recolocación y personas de edad avanzada», en Los trabajadores maduros en el contexto de la relación laboral (Álvarez CorTÉs, J.C., director), Ediciones Laborum. 
Costa Reyes, Antonio (2019). «Fomento del empleo en los viernes sociales. A propósito del RD-Ley 8/2019", Temas Laborales, n. ${ }^{\circ} 148$.

Cruz Villalón, Jesús (2019). «La centralidad del trabajo digno en un nuevo modelo social», Revista Internacional, y Comparada de Relaciones Laborales y Derecho del Empleo, vol. 7, n. ${ }^{4}$, ADAPT.

Domínguez Morales, Ana (2018). «Colectivos excluidos o postergados y negociación colectiva», en "Pobreza en la ocupación e instrumentos de reacción» (GALA DURáN, C. y Calvo Gallego, F.J., directores), Ediciones Laborum.

Fernández Villazón, Luis Antonio (2019). «La OIT y los grupos vulnerables. Especial atención a la vulnerabilidad de género y a la protección de la infancia», Revista de Trabajo y Seguridad Social, CEF, n. ${ }^{\circ} 434$.

Fernández Villazón, Luis Antonio (2016). "Grupos vulnerables: apuntes para un concepto jurídico-social», Revista de Trabajo y Seguridad Social, CEF, n. 404.

García Aguilera, Francisco José (2020). «Inclusión sociolaboral de personas con especiales dificultades de acceso al empleo. Una experiencia piloto", disponible en https:// riuma.uma.es/xmlui/handle/10630/19558 (acceso 17-10-2021).

García QuiÑones, Juan Carlos (2012). «Caracterización de las políticas activas de empleo», en AA.VV., Fernando Valdés Dal-Ré y Gemma Sobrino González, «Comentarios a la Ley de Empleo», La Ley.

Illanes Segura, Rocío (2020). «Políticas públicas para el fomento del empleo en España: un análisis pedagógico», Laplage em Revista (Sorocaba), vol. 6, n. ${ }^{\circ} 2$.

Miñarro Yanini, Margarita (2017). "La protección sociolaboral de los refugiados como grupo vulnerable: balance crítico y propuestas de mejora", Nueva revista española de Derecho del Trabajo, n.o 203.

PÉrez Campos, Ana Isabel (2010). «Personas en riesgo o situación de exclusión social: identificación del colectivo a efectos de la política de empleo. Factores relacionados con el empleo que inciden en la situación de exclusión social», en VV.AA. SAN MARTín MAzzucconi, Carolina: «La política de empleo como instrumento de inclusión social: un análisis jurídico», Servicio de Publicaciones Universidad Rey Juan Carlos.

Pérez del Prado, Daniel (2017). «La activación de las políticas de empleo: eficiencia de los principales mecanismos jurídicos», en «Reflexiones y propuestas sobre protección social y empleabilidad para jóvenes y parados de larga duración (Mercader Uguina y Pérez del Prado, directores)", Monografías de Tirant lo Blanch.

VV.AA., Barcelón Cobedo, Susana y González Ortega, Santiago (2020). El ingreso mínimo vital (comentarios al Real Decreto-Ley 20/2020, de 29 de mayo), Tirant lo Blanch.

VV.AA., De la Rica, Sara; Gorjón, Lucía; Lizarraga, Imanol (2021). La evaluación como proceso de aprendizaje Una necesidad del presente, una inversión de futuro. Información Comercial Española, ICE: Revista de economia, n. ${ }^{\circ} 102$. 